\title{
Patterns of treatment and associated short-term outcomes of unruptured intracranial aneurysms in children
}

\author{
Ganesh Asaithambi • Malik M. Adil • Kavisha M. Shah • \\ Lori C. Jordan • Adnan I. Qureshi
}

Received: 8 April 2014 / Accepted: 9 April 2014 /Published online: 22 April 2014

(C) Springer-Verlag Berlin Heidelberg 2014

\begin{abstract}
Background The rates and outcomes of treatments for intracranial aneurysms have not been exclusively determined within the pediatric population. We determined the rates of endovascular and microsurgical treatments for unruptured intracranial aneurysms (UIA) and associated rates of favorable outcome in patients aged $<18$ years.

Methods We analyzed data obtained as part of the Kids' Inpatient Database between 2003 and 2009 with primary diagnosis of UIA. Patients undergoing endovascular treatment were compared to those undergoing microsurgical treatment. We determined rates of intracerebral hemorrhage, subarachnoid hemorrhage, neurological complications, and favorable outcome.

Results There were 818 cases of UIA during the study period. A total of 111 patients (mean age $14 \pm 6$ years, $37.6 \%$ female) underwent microsurgical treatment, and another 200 patients (mean age $13 \pm 7$ years, $42.5 \%$ female) underwent endovascular treatment. A high rate of favorable outcome
\end{abstract}

Portions of this work were presented in poster form at the American Academy of Neurology Annual Meeting 2013 and the American Heart Association International Stroke Conference 2014.

G. Asaithambi $(\bowtie)$

Department of Neurology, University of Florida College of

Medicine, HSC Box 100236, Gainesville, FL 32610, USA

e-mail: ganesh785@gmail.com

G. Asaithambi · M. M. Adil • A. I. Qureshi

Zeenat Qureshi Stroke Research Institute, St. Cloud, MN, USA

K. M. Shah

Department of Pediatrics, University of Florida College of Medicine, Gainesville, FL, USA

L. C. Jordan

Department of Pediatrics, Division of Pediatric Neurology,

Vanderbilt University School of Medicine, Nashville, TN, USA was observed in patients who received either treatment (microsurgical treatment $87.7 \%$ versus endovascular treatment $91.6 \%, p=0.4)$. There was a trend towards a significantly shorter mean hospitalization stay among those who received endovascular treatment compared with microsurgical treatment ( $6 \pm 12$ versus $9 \pm 11$ days, $p=0.06$ ). There was a significant trend towards higher utilization of endovascular treatment as opposed to microsurgical treatment from 2003 to $2009(p=0.02)$.

Conclusions Although outcomes except for length of stay were comparable between endovascular treatment and microsurgical treatment patients, there was a trend towards higher utilization of endovascular treatment among children with UIAs from 2003 to 2009.

Keywords Endovascular treatment · Surgery $\cdot$ Unruptured intracranial aneurysm

\section{Introduction}

The incidence of intracranial aneurysms is estimated to range from 0.5 to $4.6 \%$ among those 18 years of age or younger [ 1 , $3,8,10-12]$. Aneurysms in the pediatric population differ significantly from those in the adult population. These different features include predominance among boys, a higher incidence of aneurysms in the posterior circulation and the internal carotid artery bifurcation, and a higher incidence of giant aneurysms $[1,3]$. The three major pathophysiological mechanisms found among children that may result in intracranial aneurysms are trauma, infection, and dissection, which are less common among the aneurysms that exist within the adult population [6]. The International Study of Unruptured Intracranial Aneurysms examined the natural history and effects of treatment on unruptured intracranial aneurysms (UIA) and included patients of all ages [2]. However, the rates and 
outcomes of treatments for intracranial aneurysms have not been exclusively determined within the pediatric population. We determined the frequency of endovascular and microsurgical treatments for UIA and associated proportion of favorable outcomes in patients aged $<18$ years using nationally representative data.

\section{Methods}

We obtained data samples from the Kids' Inpatient Database, which is part of the Healthcare Cost and Utilization Project (HCUP). A comprehensive overview of this database is available at http://www.hcup-us.ahrq.gov/kidoverview.jsp. If there were fewer than 11 discharges for a given variable, that respective variable was excluded from analysis to avoid biased statistical weighting of small sample sizes and to fulfill the requirements for use of the data set. We used the International Classification of Diseases, Ninth Revision, Clinical Modification (ICD-9-CM) primary or secondary diagnosis codes 437.3 to identify patients admitted with unruptured intracranial aneurysms. We also used the ICD-9CM procedure codes 39.51 to identify microsurgical treatment and 39.71-39.79 and 39.52 to identify endovascular treatment of aneurysms.

Study variables examined included age, gender, race/ethnicity, and comorbidities obtained from the AHRQ comorbidity data files including hypertension and chronic lung disease. The ICD-9-CM diagnosis codes were used to identify nicotine dependence (305), subarachnoid hemorrhage (430), and intracerebral hemorrhage (431-432). The ICD-9$\mathrm{CM}$ procedure codes allowed estimation of the percentage of patients who underwent procedures such as cerebral angiography (88.41), transfusion (99.4), and intubation (96.04).

We determined composite rate of adverse events including neurological complications, intracerebral hemorrhage (ICH), and subarachnoid hemorrhage (SAH). Favorable outcome was defined as the rate of discharge to home/self-care. Lengths of stay and hospital charges were also examined.

Statistical analysis was performed using SAS 9.3 software (SAS Institute, Cary, NC). We performed univariate analysis, chi-square for categorical variables, and $t$ test for continuous variables to identify differences in the study variables and endpoints between two groups.

\section{Results}

There were 818 cases of UIA between 2003 and 2009. A total of 111 patients (mean age $14 \pm 6$ years, $37.6 \%$ female) underwent microsurgical treatment, and 200 patients (mean age $13 \pm 7$ years, $42.5 \%$ female) underwent endovascular treatment (Table 1). A high rate of favorable outcome was
Table 1 Demographic and clinical characteristics of pediatric patients who received either microsurgical or endovascular treatment of unruptured intracranial aneurysms

\begin{tabular}{|c|c|c|c|}
\hline & $\begin{array}{l}\text { Microsurgical } \\
\text { treatment }\end{array}$ & $\begin{array}{l}\text { Endovascular } \\
\text { treatment }\end{array}$ & $p$ value \\
\hline Overall number & 111 & 200 & \\
\hline Age mean (SD) & $14(6)$ & $13(7)$ & 0.2 \\
\hline Women $(\%)$ & $41(37.6)$ & $84(42.5)$ & 0.5 \\
\hline \multicolumn{4}{|l|}{ Race/ethnicity (\%) } \\
\hline $\begin{array}{l}\text { White } \\
\text { African American }\end{array}$ & $\begin{array}{l}54(60) \\
7(8.5)\end{array}$ & $\begin{array}{l}93(58.0) \\
20(12.3)\end{array}$ & \multirow[t]{3}{*}{0.2} \\
\hline Hispanic & $20(23.0)$ & $26(16.1)$ & \\
\hline Other & $8(8.5)$ & $22(13.5)$ & \\
\hline \multicolumn{4}{|l|}{ Comorbid conditions } \\
\hline Hypertension & $7(6.0)$ & $18(9.2)$ & 0.4 \\
\hline Chronic lung disease & $4(3.9)$ & $9(4.4)$ & 0.8 \\
\hline Nicotine dependence & $6(5.7)$ & $9(4.7)$ & 0.7 \\
\hline \multicolumn{4}{|l|}{ In-hospital procedure } \\
\hline Angiography & $128(64.3)$ & $71(64.8)$ & 0.9 \\
\hline Intubation & $3(3.1)$ & $8(4.1)$ & 0.7 \\
\hline Transfusion & $7(6.7)$ & $11(5.5)$ & 0.7 \\
\hline Mean length of stay (SD) & $9(11)$ & $6(12)$ & 0.06 \\
\hline $\begin{array}{l}\text { Mean hospital charges } \\
\text { (SD) }\end{array}$ & $\begin{array}{l}114,765 \\
\quad(144,174)\end{array}$ & $\begin{array}{l}105,998 \\
\quad(144,528)\end{array}$ & 0.9 \\
\hline Favorable outcome $(\%)$ & $97(87.7)$ & $183(91.6)$ & 0.4 \\
\hline \multicolumn{4}{|l|}{ In-hospital events } \\
\hline $\mathrm{ICH} / \mathrm{SAH}$ & $22(19.8)$ & $23(11.5)$ & 0.06 \\
\hline $\begin{array}{l}\text { Neurological } \\
\text { complications }^{\mathrm{a}}\end{array}$ & $7(6)$ & $10(4.9)$ & 0.7 \\
\hline Hydrocephalus & $7(6.6)$ & $14(7.1)$ & 0.8 \\
\hline
\end{tabular}

$I C H$ intracerebral hemorrhage, $S A H$ subarachnoid hemorrhage

${ }^{a}$ Other neurological complications defined as any central nervous system dysfunction that does not include a cerebrovascular event

observed in patients who received either treatment (microsurgical treatment $87.7 \%$ versus endovascular treatment $91.6 \%$, $p=0.4)$. There was a significant overall trend towards higher utilization of endovascular treatment as opposed to microsurgical treatment from 2003 to 2009 ( $p=0.02$ ), though there was some variability from year to year (Fig. 1). There was a trend towards a significantly shorter mean hospitalization stay among those who received endovascular treatment as opposed to microsurgical treatment ( $6 \pm 12$ versus $9 \pm 11$ days, $p=0.06$ ). This, however, was not accompanied by significant differences in mean hospital charges (microsurgical treatment $\$ 114,765 \pm 144,174$ versus endovascular treatment $\$ 105,998$ $\pm 144,528, p=0.9$ ).

$\mathrm{ICH}$ and SAH occurred with higher frequencies in the microsurgical treatment group as compared to those in the endovascular treatment group, but this did not reach significance (microsurgical treatment $19.8 \%$ versus endovascular treatment $11.5 \%, p=0.06$ ). There was a similar rate of 
Fig. 1 Method of treatment for unruptured intracranial aneurysms in children by year

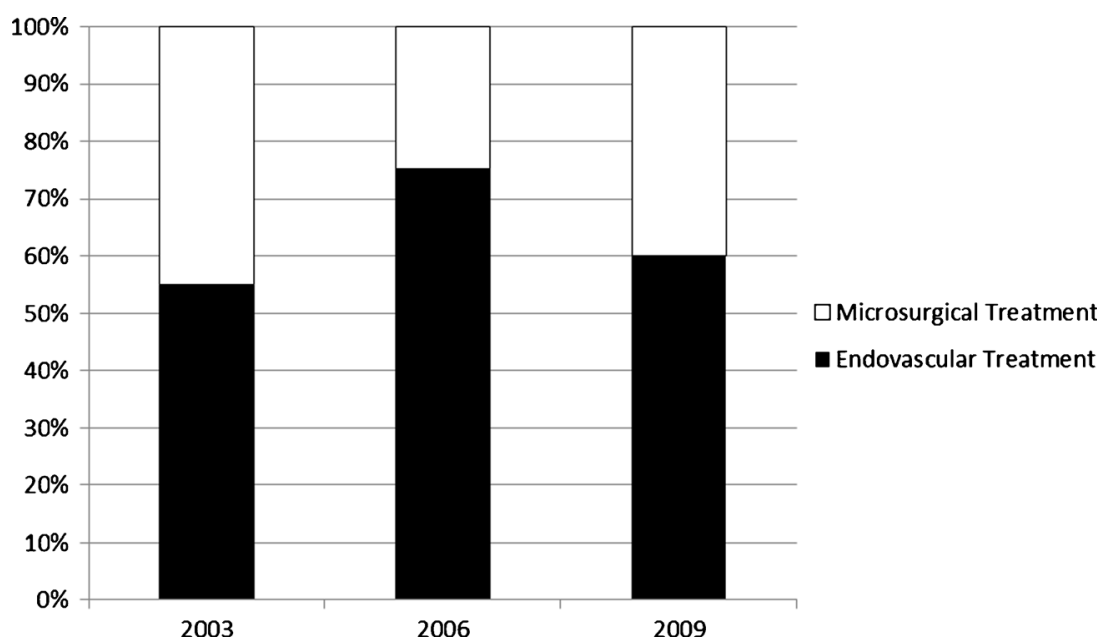

favorable outcome between these groups as well (microsurgical treatment $79 \%$ versus endovascular treatment $82.4 \%, p=$ $0.8)$. There were no differences in the rates of neurological complications $(p=0.7)$, which excluded cerebrovascular events, and hydrocephalus ( $p=0.8$, Table 1$)$.

\section{Discussion}

Kakarla and colleagues report that approximately $62 \%$ of pediatric UIA are symptomatic [5]. Discovery of UIA is linked to presentations with seizures, non-SAH-related headaches, or another neurological deficit approximately $40 \%$ of the time $[3,6]$. Dissecting aneurysms in particular can lead to mass effect, hemorrhage, or ischemia [6]. There are few reports of incidentally found UIA in children during routine autopsy studies $[6,8]$. Given that a majority of pediatric UIAs are symptomatic, treatment is important in order to prevent aneurysm rupture or worsening of symptoms due to UIA. With different pathophysiological mechanisms for the development of intracranial aneurysms among children, it is important to understand the implications of the two current treatments for intracranial aneurysms. Using nationally representative data, we demonstrated that there was no difference in short-term outcomes between endovascular and microsurgical treatments and that the rate of complications including $\mathrm{ICH}$, $\mathrm{SAH}$, and other neurological complications were not significantly different. Hospitalization length, while not reaching significance, was shorter among those who received endovascular treatment, but there was no difference in hospital costs.

Durability is of concern when selecting an intervention in children with UIA due to the longer life expectancy [3, 12, 13]. Kakarla and colleagues retrospectively evaluated this question in 48 children with angiographic follow-up ranging 5-120 months and reported that both endovascular and microsurgical treatments achieved similar results in outcomes and suggested that microsurgical treatment may be equivalent to or better than endovascular treatment for conferring longterm durability and protection; however, follow-up was only reported in $54 \%$ of cases reviewed [5]. Sanai and colleagues reported that while both treatments were fairly successful, endovascular treatment is associated with a recurrence rate of 20-40\%; therefore, microsurgical treatment may be more effective in permanently obliterating aneurysms [10,11]. Approximately $21 \%$ of children who received endovascular treatment required re-treatment of the index aneurysm $[1,3]$. Despite concerns for durability of endovascular treatment in pediatric UIA, we observed that there was a significant trend towards using endovascular treatment as opposed to microsurgical treatment for treating children with UIA. This treatment shift in children follows the same pattern as in adults with aneurysms [7].

Our study has limitations. With large databases, inaccuracies in coding can affect patient identification and result in underestimation of the proportion of patients in the groups created for comparison; however, a prior validation study for identifying the treatment courses of UIAs showed high specificity [4]. The events of SAH or ICH during hospitalization may have occurred prior to or after microsurgical or endovascular treatments. We were able to ascertain the presence of ICH or SAH by using the ICD-9-CM codes, but were unable to categorize either based on severity or whether these events were even related to the target aneurysm. Therefore, it remains unclear what resulted in these high rates of hemorrhages. The high rate of favorable outcomes $(\sim 80 \%)$ suggests that these were minor events with unclear relevance to the procedures. While there are variations in etiology, size, and locations of UIAs between children and adults, we are unable to ascertain the specific etiologies, sizes, or locations of the UIAs treated within our study population. We are also limited in our ability to identify the clinical presentations and diagnostic workup of treated patients. A formal outcome scale was not used in our study, but the use of "discharge home" as an 
outcome has a high predictive value for modified Rankin scale scores $<2$ at 3 months in adults [9].

\section{Conclusion}

While the length of stay among children who receive endovascular treatment for UIA is usually reduced, the short-term outcomes for UIA treatment are not significantly different between endovascular and microsurgical treatments. There is a trend towards higher utilization of endovascular treatment among children with UIAs from 2003 to 2009. Future studies should investigate long-term angiographic and clinical results of both treatments using a prospective trial design.

Disclosure The authors have not received any financial support for this work from any organization. A.I.Q. has received funding from the National Institutes of Health U01-NS062091-01A2 (medication provided by EKR Therapeutics), the American Heart Association Established Investigator Award $0840053 \mathrm{~N}$, and the Minnesota Medical Foundation, Minneapolis, MN. The rest of the authors do not report any other conflicts of interest.

\section{References}

1. Hetts SW, Narvid J, Sanai N, Lawton MT, Gupta N, Fullerton HJ, Dowd CF, Higashida RT, Halbach VV (2009) Intracranial aneurysms in childhood: 27-year single-institution experience. AJNR Am J Neuroradiol 30:1315-1324

2. International Study of Unruptured Intracranial Aneurysms Investigators (2003) Unruptured intracranial aneurysms: natural history, clinical outcome, and risks of surgical and endovascular treatment. Lancet 362:103-110

3. Jian BJ, Hetts SW, Lawton MT, Gupta N (2010) Pediatric intracranial aneurysms. Neurosurg Clin N Am 21:491-501

4. Johnston SC, Dudley RA, Gress DR, Ono L (1999) Surgical and endovascular treatment of unruptured cerebral aneurysms at university hospitals. Neurology 52:1799-1805

5. Kakalra UK, Beres EJ, Ponce FA, Chang SW, Deshmukh VR, Bambakidis NC, Zabramski JM, Spetzler RF (2010) Microsurgical treatment of pediatric intracranial aneurysms: long-term angiographic and clinical outcomes. Neurosurgery 67:237-249

6. Krings T, Geibprasert S, terBrugge KG (2010) Pathomechanisms and treatment of pediatric aneurysms. Childs Nerv Syst 26:13091318

7. Lin N, Cahill KS, Frerichs KU, Friedlander RM, Claus EB (2012) Treatment of ruptured and unruptured cerebral aneurysms in the USA: a paradigm shift. J Neurointerv Surg 4:182-189

8. Mehrotra A, Nair AP, Das KK, Srivastava A, Sahu RN, Kumar R (2010) Clinical and radiological profiles and outcomes in pediatric patients with intracranial aneurysms. J Neurosurg Pediatr 10:340 346

9. Qureshi AI, Chaudhry SA, Sapkota BL, Rodriguez GJ, Suri MF (2012) Discharge destination as a surrogate for Modified Rankin Scale defined outcomes at 3-and 12-months poststroke among stroke survivors. Arch Phys Med Rehabil 93:1408-1413

10. Sanai N, Auguste KI, Lawton MT (2010) Microsurgical management of pediatric intracranial aneurysms. Childs Nerv Syst 26:13191327

11. Sanai N, Quinones-Hinojosa A, Gupta NM, Perry V, Sun PP, Wilson CB, Lawton MT (2006) Pediatric intracranial aneurysms: durability of treatment following microsurgical and endovascular management. J Neurosurg 104:82-89

12. Stiefel MF, Heuer GG, Basil AK, Weigele JB, Sutton LN, Hurst RW, Storm PB (2008) Endovascular and surgical treatment of ruptured cerebral aneurysms in pediatric patients. Neurosurgery 63:859865

13. Vasan R, Patel J, Sweeney JM, Carpenter AM, Downes K, Yousef AS, van Loveren H, Agazzi S (2013) Pediatric intracranial aneurysms: current national trends in patient management and treatment. Childs Nerv Syst 29:451-456 